\title{
Investigating Nonnative TEFL Students' Self-Regulation in an Online Learning Environment
}

\author{
Safaa M. Khali1 ${ }^{1 \& 2}$ \\ ${ }^{1}$ Department of English, Zulfi College of Education, Majmaah University, Al-Majmaah, Saudi Arabia \\ ${ }^{2}$ Department of Languages, Sadat Academy for Management Sciences, Cairo, Egypt \\ Correspondence: Safaa M. Khalil, Department of English, Zulfi College of Education, Majmaah University, \\ Al-Majmaah, 11952, Saudi Arabia. E-mail: safaa.k@mu.edu.sa
}

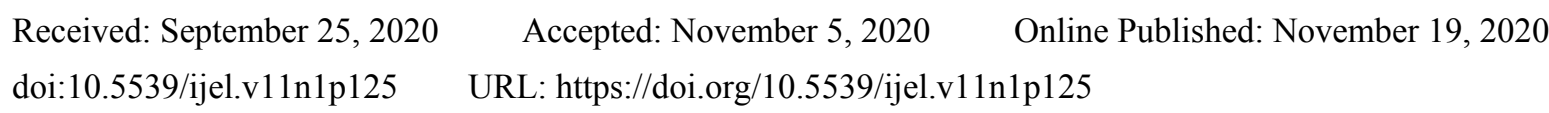

\begin{abstract}
Coping with technological revolution has become unavoidable in the educational process. In addition to the various advantages of integrating technology into the traditional classroom, utilizing it has been compulsory as an inevitable solution to a global crisis such as the Coronavirus pandemic that we face these days. The present study, using a case study design, aims at exploring self-regulatory strategies that undergraduate university students practice while engaging in virtual classrooms. Participants of the study were 187 university students from all levels. They are all majoring in Teaching English as a Foreign Language (TEFL). Data were collected using mixed method approach in which two tools of measurement were used in the research. An online questionnaire was administered to the participants, then online focus group interviews were conducted. Data gathered were analyzed statistically and findings revealed that non-native TEFL students are high-level self-regulatory learners with no significant effect of university level on students' self-regulation. In addition, pedagogical recommendations were displayed.
\end{abstract}

Keywords: online learning, self-regulatory learning, EFL learning

\section{Introduction}

Self-regulation is a critical factor not only for students' success at college, but also for personal success in life. It promotes autonomy, self-dependence and self-awareness which in turn lead to developing successful life-long learners and consequently highly productive persons. Therefore, the objective of present study is to analyze students' practices in online classes and examine the relationship between enrolling in this type of learning and the development of self-regulatory strategies for Saudi students majoring in English language at Majmaah University. The review of the literature is divided into four sections. The first section displays the features of online learning. The second section defines self-regulatory learning. The third section presents the reciprocal relationship between self-regulatory learning and successful online learners. The final section deals with self-regulatory learning and its association with the strategies necessary for language learning.

Therefore, the present study aims at investigating the self-regulatory strategies that Saudi students majoring in English language tend to develop while engaging in virtual classrooms. Therefore, the present study aims at answering the following questions:

1) What are the most frequently used self-regulatory learning strategies that TEFL students use in online classrooms?

2) Is there a significant relationship between students' university level and their use of self-regulatory learning strategies?

3) Is there a significant relationship among the six subscales of self-regulatory learning strategies?

4) What are TEFL students' attitudes towards online learning as a self-regulatory learning environment? 


\section{Literature Review}

\subsection{Online Learning}

Online learning has become an indispensable part of education nowadays. In their systematic review of the studies that aimed at defining online learning in the past 30 years, Singh and Thurman (2019) provided different characteristics of online learning. They believe that it is the type of learning that is basically web-based or depends mainly on the Internet. The classroom in such learning environment is virtual which means, there is no face-to-face communication between the instructor and the students. Online learning can be synchronous where the students and the instructor engage in the learning activity at the same time. It can also be asynchronous in which the students have the option to choose the convenient time for their learning experience (Hung et al., 2010). Leaving the choice to the learners to decide upon the time and the place that best suit them is one of the features of self-regulatory learning.

\subsection{Self-Regulatory Learning}

Self-regulation is neither a cognitive ability nor an academic skill. According to Zimmerman (2000, p. 65), "Self-regulation refers to self-generated thoughts, feelings, and behaviors that are oriented to attaining goals". Following Bandura's social cognitive theory, self-regulatory learning develops from the interaction between personal, behavioral and environmental factors in an iterative rather than cyclical process (Barnard-Brak et al., 2010). Such interaction requires the learner to plan and set goals, monitor, control and evaluate his/her own learning (Panadero, 2017). Self-regulation can be attained by certain strategies which depend mainly on learners' ability to monitor, regulate and evaluate their own cognitive, affective and behavioral strategies towards achieving previously set goals (Pintrich, 2000; Zimmerman, 2002; Zimmerman \& Schunk, 2011). Therefore, self-regulatory learners tend to be proactive rather than active (Khiat, 2015; Kirmizi, 2015). Accordingly, Zimmerman (2013) asserted that proactivity, perservance and ability to adapt are fundamental traits that every self-regulatory learner should possess. In addition, he contended that self-regulatory learning couldn't be achieved through covert cognitive processes alone, they should be accompanied by overt behavioral attitudes from the learner such as structuring convenient environment or seeking help from others. Covert and overt processes exist in all learners however what distinguishes expert from novice learners are the quality and consistency of their processes.

Various models of self-regulatory learning have been proposed (Boekaerts, 1991; Winne \& Hadwin, 1998; Pintrich et al., 1998). Among the most influential of them is that of Zimmerman (2000, 2015). According to him, self-regulatory learning has three phases: forethought phase, performance phase, and self-reflection phase. In the forethought phase, the learner gets involved into processes needed before learning such as inducing self-motivation beliefs and interests, defining expected outcomes, analyzing the task, setting goals and planning to achieve them. In the performance phase that happens while learning, the learners engage in two types of processes; self-control and self-observation processes that maximize learning. Examples of these processes include time management and self-observation strategies as metacognitive monitoring and self-recording. The final phase of self-regulatory learning is the self-reflection phase in which the learners evaluate their own learning outcomes to get feedback either positive or negative. When the feedback is positive, the learners are described as proactive as they possess the ability to induce adaptive inferences that enable them to modify their learning strategies to optimize learning outcomes. In contrast, reactive learners produce negative feedback that triggers defensive inferences that affect learners' self-motivation, that should be boosted in the forethought phase, thus hindering the recursiveness of the cycle (Zimmerman, 2013, pp. 143-144).

The three phases of self-regulation are analogous to the three processes of planning, monitoring and evaluating that are the basic components of metacognition. Metacognition refers to learner's awareness and control of his/her own learning (Feryal, 2008; Harris, 2003; Anderson, 2002). Self-regulation is the outcome where metacognition and motivation intersect (Zimmerman, 2013). Metacognitive processes lead to increasing motivation which in turn enhances high levels of self-regulation. This view was supported by varies recent research (Williamson, 2015; Tzohar-Rozen \& Kramarski, 2014) which asserted the interconnectedness among the three aspects.

\subsection{Reciprocal Relationship Between Self-Regulatory Learning and Successful Online Learning}

The relationship between the type of learning and the development of students' self-regulatory learning strategies is reciprocal. Well-structured learning environment is predicted to enhance students' self-regulation and the use of self-regulatory strategies proved to enhance students' engagement and hence lead to better achievement. Broadbent and Poon (2015) investigated students' self-regulatory learning strategies in two learning environments. A survey was administered to 140 students enrolled in online classes and 466 students engaged in 
blended learning. Findings showed that online students are more self-regulatory learners than blended learning students.

Self-regulatory learning proved to positively affect students' academic achievement in both traditional face-to-face classes and online learning environment. In a recent study, Sun et al. (2018), examined the relationships between academic achievement and self-regulatory constituents in Math courses instructed with flipped classes, the results clarified that students' self-regulation strategies were positively related to academic achievement in a significant manner. Parallel findings were revealed by Kizilcec et al. (2017). They examined self-regulatory learning strategies in six Massive Open Online Courses (MOOC), a survey was administered to 4,831 students. Results revealed that the self-regulatory strategies of goal setting and strategic planning are helpful to students' engagement in MOOCs. In addition, those strategies proved to have positive impact on students' achievement. Accordingly, Bradley et al. (2017) studied the effect of self-regulation and self-efficacy on students' achievement in online learning environment. Findings indicated that students' self-efficacy beliefs are closely correlated with students' self-regulatory strategies which has a direct impact on their academic outcomes. A parallel conclusion was reported by Pardo et al. (2016) in their study which explored the relationship between self-regulation and students' online activities and academic performance. In their study, Zhu et al. (2016) investigated the relationship between university students' self-regulatory learning and learning outcomes in blended learning environment. Results showed that there's a positive relationship between self-regulatory learning and better learning outcome.

\subsection{Self-Regulatory Learning and Language Learning}

Self-regulation, given various names such as learner self-management, self-directness and autonomy is proved to be the key factor for success in language learning (Zimmerman \& Schunk, 2011). Successful language learners are self-regulated learners who are able to efficiently implement appropriate language learning strategies in their learning experience (Anderson, 1991; Bin, 2008; O’Malley \& Chamot, 1990; Singhal, 2001). An excellent example of the integral relationship between self-regulatory learning and language learning is Oxford's (2011) Strategic Self-Regulation ( $\left.S^{2} R\right)$ Model. Oxford (2017) advocates that learning strategies are the tools that learners implement to activate self-regulated cognitions, emotions and behaviors. Variant language learning strategies can fit in each of Zimmerman's three phases of self-regulation: the forethought phase, the performance phase, and the self-reflection phase.

In the forethought phase, language learning strategies such as task analysis, planning and regulating emotions are commonly used by the language learner. In the performance phase, self-monitoring strategies by which the learner monitors his own performance during the task in order to examine the efficiency of strategies used and switch them when required. These strategies include cognitive and volition-regulating strategies. Self-evaluation strategies are deployed by language learner in the self-reflection phase which is the final phase of self-regulation. Therefore, in the field of language learning, self-regulation is the skill and the language learning strategies are the constituent strategies required to master such skill.

\section{Methodology}

This study used a case study design assigning the mixed- method approach to collect data. This approach helped in achieving complementarity. Complementarity refers to examining the various aspects or layers of the phenomenon being investigated (Riazi \& Candlin, 2014). In the present study, there are two points intended for investigation. The first is the level of self-regulation that university students possess in online learning. Data needed for this aspect were collected through a questionnaire. The other area of investigation is university students' attitudes towards online learning from the perspective of self-regulatory. This was examined by conducting focus group interviews. Collected data were analyzed quantitatively and qualitatively

\subsection{Participants}

187 Saudi undergraduate students from Majmaah University with its different branches participated in the present study. 156 of the participants were females $(83.4 \%)$ while $31(16.6 \%)$ were male. They were all students in the Department of English Language at different levels. Their ages ranged from 18 to 21. Participants were from four university branches: $44.9 \%$ from Al-Zulfi, 29.4\% from Majmaah, 18.2\% from Hotat Sodair and 7.5\% from Al-Ghat. Based on their university level, participants were grouped into four classes. Class A that constituted $16.6 \%$ of the participants were from students in levels 1 and 2. Class B (23\%) contained students in levels 3 and 4 . Students in levels 5 and 6 with a percentage of 32.6 composed Class C. Class D represented students in levels 7 and 8 with $27.8 \%$ (see Appendix A). 


\subsection{Instruments of Measurement}

\subsubsection{The Online Self-Regulatory Learning Questionnaire (OSLQ)}

There are two instruments of measurement implemented in the present study; a questionnaire and focus group structured interviews. The first instrument is the Online Self-Regulatory Learning Questionnaire (OSLQ), adopted with permission from Barnard-Brak et al. (2010). The questionnaire is designed to assess students' self-regulation skill represented in the six subscales that constitute self-regulatory strategies. These subscales are goal setting, environment structuring, task strategies, time management, help seeking, and self-evaluation displayed in the 24 items of which the questionnaire is composed. Subjects were asked to respond on a five-point Likert scale ranging from 1 that indicates "never" to 5 which represents "most of the time".

Various surveys have been designed to assess self-regulation (Carey et al., 2005; Winne \& Perry, 2000; Tseng et al., 2006), however, the main reason for choosing this particular questionnaire is that it was carefully designed to assess self-regulation in the online as well as blended learning environments with high reliability. Barnard-Brak et al. (2010) reported high internal consistency of the OSLQ on both overall scores level $(\alpha=.90)$ as well as subscale scores level in which Cronbach alpha ranged from .85 to .92 (p. 65). When replicated in the present study, internal consistency reliability measured by Cronbach's alpha was 90 for the overall scores and ranged from 60 to 75 (Table 1) for the subscale scores.

Table 1. Reliability coefficients for the OSLQ

\begin{tabular}{llll}
\hline Self-regulatory Learning strategies Subscale & No. of items & Cronbach's Alpha Coefficient \\
\hline 1. & Goal Setting & 5 & .66 \\
2. $\quad$ Environment Structuring & 4 & .72 \\
3. $\quad$ Task Strategies & 4 & .64 \\
4. Time Management & 3 & .75 \\
5. Help Seeking & 4 & .60 \\
$6 . \quad$ Self-evaluation & 4 & .69 \\
\multicolumn{2}{l}{ Total } & 24 & .90 \\
\hline
\end{tabular}

To examine the content validity, the questionnaire was submitted to two jurors in the field of English language teaching. Using Google Forms, an online version of the questionnaire was prepared, and the link was sent to the participants.

\subsubsection{Online Focus Group Interview}

The second instrument is a semi-structured focus group interview in which open-ended questions were asked and probes were used to elicit detailed responses from the participant interviewees. This instrument was used to investigate students' attitudes towards online learning as a self-regulatory learning environment. Five focus group interviews were conducted. Each group consisted of six participants. Choosing focus-group rather than individual interviews was intended because of its dynamic nature which widens the range of information and enriches the data obtained (Rabiee, 2004).

\subsection{Procedures}

There are two steps in the procedures of the present study. First, students were asked to respond to the online questionnaire. Then, online focus group interviews were conducted. The interview questions were semi-structured as specific open-ended questions were prepared beforehand. Each interview lasted for about 45 minutes and was audio-recorded.

\subsection{Data Analysis}

Both quantitative and qualitative data analyses were conducted in the present study. IBM SPSS version 20 was used to analyze data quantitatively. In the beginning, participants' responses to the questionnaire items were coded and data were tested for normality using the Kolmogorov-Smirnov test which proved that data were normally distributed. Then, descriptive and inferential analyses were applied.

Interviews were conducted using open-ended questions. Probes were used to elicit detailed responses. All interviews were audio-recorded and transcribed verbatim. Then a content analysis method was used to analyze interview data. Transcribed data were read 'literally' and 'interpretively' to infer any additional information not explicitly stated by the participants for the sake of appropriate 'categorical indexing' of the data reported by the students (Mason, 2002, pp. 149-150). The deductive or direct approach of content analysis was followed (Hsieh 
\& Shannon, 2005) and the themes coded were: awareness of self-regulation in online classes, positive attitudes in addition to negative attitudes towards online learning.

\section{Results}

\subsection{Research Question 1: The Most Frequently Used Self-Regulatory Learning Strategies in Online Classes}

Regarding the five-point likert-scale, and with the use of SPSS, a new variable labeled level of self-regulation was computed based on the rating scales of the questionnaire items. As displayed in Table 2, the five scales were grouped into three levels of self-regulation: low, moderate and high.

Table 2. The three levels of self-regulation

\begin{tabular}{lll}
\hline Mean & Likert-scale & Level of self-regulation \\
\hline $1.00-1.79$ & Never & low \\
$1.80-2.59$ & Few times & \\
$2.60-3.39$ & Not sure & Moderate \\
$3.40-4.19$ & Sometimes & High \\
$4.20-5.00$ & Most of the time & \\
\hline
\end{tabular}

While Low-level self-regulated subjects are those who scored from 1 to 2.59 , moderate-level subjects have means ranged from 2.60 to 3.39. Moreover, subjects with means ranged from 3.40 to 5 are considered to possess a high-level of self-regulation. Table 3 shows the results of the descriptive statistical analysis of the OSLQ. Results revealed that the overall mean of the participants' responses is 3.90 with a standard deviation (SD) .61 which indicates high level of self-regulation in general.

Table 3. Descriptive statistical analysis of the OSLQ

\begin{tabular}{llll}
\hline Self-regulatory Learning Scale & $\mathrm{N}$ & Mean & Std. Deviation \\
\hline Goal Setting & 187 & 3.9861 & .71393 \\
Environment Structuring & 187 & 4.2567 & .75466 \\
Task Strategies & 187 & 3.7406 & .80588 \\
Time Management & 187 & 3.9430 & .87188 \\
Help Seeking & 187 & 3.5602 & .86256 \\
Self-evaluation & 187 & 3.8957 & .82539 \\
Total & 187 & 3.8988 & .61316 \\
\hline
\end{tabular}

Similarly, on the scale level, results show that participants report a high level of self-regulation in each of the six scales in the questionnaire with means ranged from 3.56 for the Help Seeking subscale to 4.26 for the Environment Structuring subscale with SD .86 and .75 respectively.

Due to the inequality of the number of male and female participants, using gender as a dependent variable in analyzing data was unreliable. The researcher, instead, computed the new variable "level of self-regulation: high, moderate, and low" and calculated the percentage within each group discretely. Results indicated that high-level self-regulatory participants constitute the largest part of both groups as they are $84.6 \%$ of the females and $74.2 \%$ the males. On the other hand, few low-level self-regulatory participants existed in both groups $(1.3 \%$ and $6.5 \%$ of the female and male subjects respectively). Results of classifying students' level of self-regulation by gender are displayed in Figure 1. 


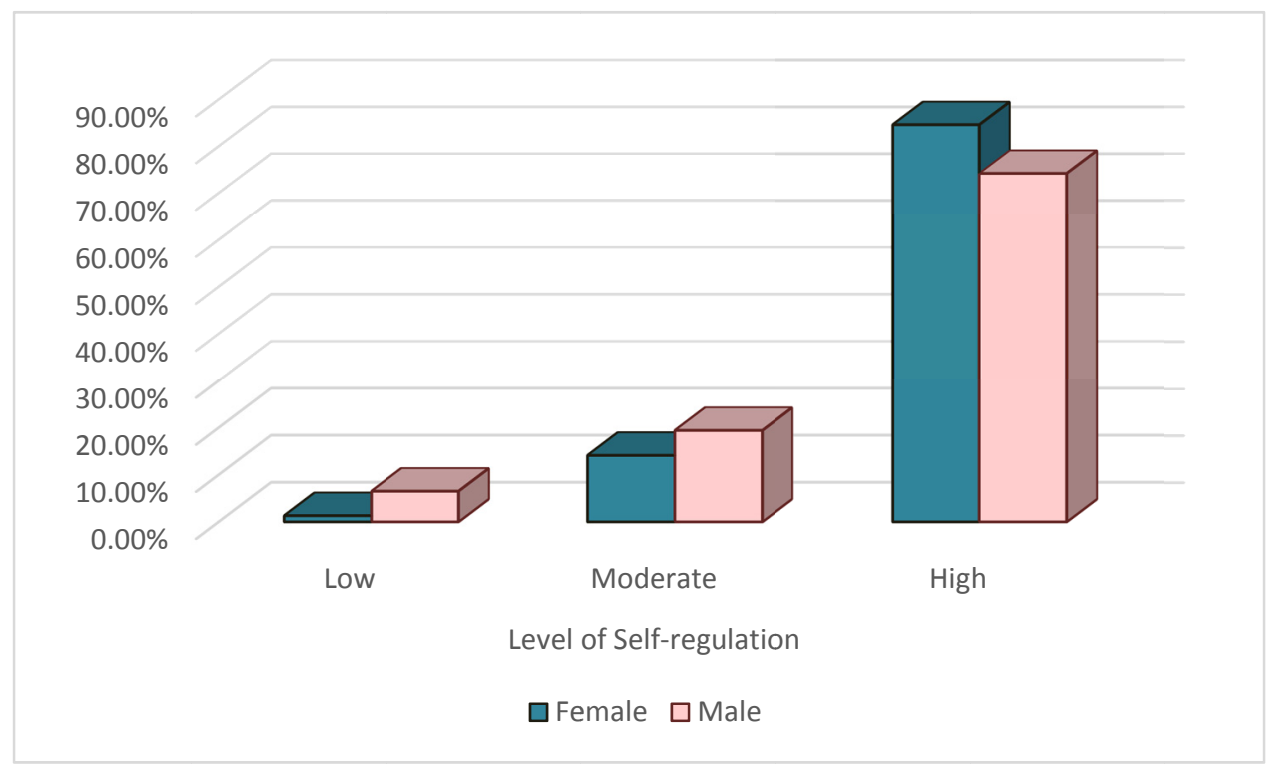

Figure 1. Levels of self-regulation by gender

Note. Percentages of low, moderate, and high self-regulation levels are shown for male and female university students

\subsection{Research Question 2: The Relationship Between Students'University Level and Their Use of Self-Regulatory Learning Strategies}

The present study makes use of students' university level as the independent variable and their use of self-regulatory strategies as the dependent variable. As the students' university level is classified into four subcategories, One-way ANOVA analysis was used to test whether there is significant difference in the students' use of self-regulation due to their university level.

Table 4. Results of one-way ANOVA analysis

\begin{tabular}{|c|c|c|c|c|c|}
\hline \multicolumn{6}{|l|}{ ANOVA } \\
\hline \multicolumn{6}{|c|}{ Self-Regulatory Strategies } \\
\hline & Sum of Squares & df & Mean Square & $\mathrm{F}$ & Sig. \\
\hline Between Groups & 1.618 & 3 & .539 & 1.445 & .231 \\
\hline Within Groups & 68.312 & 183 & .373 & & \\
\hline Total & 69.930 & 186 & & & \\
\hline
\end{tabular}

As an initial step, the homogeneity of variances among the comparison groups was ascertained with the value of Levene statistic $1.16>.05$ which strongly proves that the difference among the variances are not at all significant. Table 4 shows the results of the ANOVA that revealed $\mathrm{F}(3,183)=1.45, \mathrm{p}=.23$ is greater than .05 . This suggests that there is no significant difference in the students' use of self-regulatory strategies based on their level at university.

\subsection{Research Question 3: The Relationship Among Six Subscales of Self-Regulatory Learning Strategies}

In order to test whether there is a significant relationship between any two of the six subscales of self-regulatory learning strategies, Pearson Correlation was calculated. Results, as indicated in Table 5, proved that there is a strong positive correlation between all the six types of self-regulatory strategies when testing them in pairs as the significance value in all pair results was $p<.001$ and the $r$ ranged from .31 to .69 . When examining the results, as shown in Table 5, it is noted that the strongest relationship exists between goal setting and time-management strategies as $\mathrm{r}(185)=.69, \mathrm{p}<.01$. 
Table 5. Pearson correlation among scales of self-regulation

\begin{tabular}{cllllll}
\hline Self-Regulation Strategy & 1 & 2 & 3 & 4 & 5 & 6 \\
\hline 1. & Goal Setting & - & & & & \\
2. & Environment Structuring & $.552^{* *}$ & - & & & \\
3. & Task Strategies & $.533^{* *}$ & $.381^{* *}$ & - & & \\
$4 . \quad$ Time Management & $.687^{* *}$ & $.417^{* *}$ & $.590^{* *}$ & - & $.453^{* *}$ & - \\
$5 . \quad$ Help Seeking & $.443^{* *}$ & $.309^{* *}$ & $.474^{* *}$ & $.525^{* *}$ & $.642^{* *}$ & - \\
6. & Self-evaluation & $.617^{* *}$ & $.423^{* *}$ & $.517^{* *}$ & &
\end{tabular}

\subsection{Research Question 4: TEFL Students' Awareness and Attitudes Towards Online Learning as a Self-Regulatory Learning Environment}

In response to the first question "Do you think online classes made you more responsible for your own learning? How? most of the interviewees asserted that they became more self-dependent about their courses when attending them online. Interviewees' responses to this question confirmed the results of the descriptive statistical analysis. Most students reported being high-level self-regulatory learners in all the six scales of self-regulation. Here are examples from the students' responses:

"I listen to the recorded lecture if there is something that I didn't understand in the class. If the problem persists, I ask my teacher or my classmates"

"I allocate a specific room away of distraction and lock myself in so as none of my siblings enters"

"I prepare a pen and a notebook, and I wear my earphones for more concentration"

When asked "Do you find online learning useful and enjoyable? about half of the interviewees positively replied indicating various factors that make them enjoy online learning. These factors are:

- Concentration In online learning is much better

- Doing and turning in assignments became easier

- Being and watch it is more comfortable

- Contacting teachers became more accessible

- Online exams are easier to answer and less stressful

On the other hand, when analyzing the interviewees responses to the last question "What are the challenges that you face in online learning?", they provided the following points:

- It is hard to communicate with the teacher behind the screen.

- The quality of Internet connection is poor.

- Concentration in online learning is hard.

- Surrounding noise causes distraction.

- It is hard, exhausting and eye-straining to look at the screen for multiple hours.

- Participation in online class activity is harder.

- Falling asleep when taking the class in bedrooms

- If the time of the lecture is changed and the new time may not suitable for all.

- Technical problems in the electronic exams

\section{Discussion}

The major finding of the present study is that, in an online learning environment, Saudi TEFL students; female and male, are found to be high-level self-regulatory learners. It is conceivable that the nature of online classes and the relevant activities prompted the learners to independently rely on their own learning strategies. When interviewed, students in the present study reported relying on specific planning and self-evaluation strategies they developed by themselves to overcome learning challenges. This finding accords with multiple research that proved that an online learning environment, in comparison to face-to-face or blended learning environments, allowed learners to succeed in taking the responsibility of their own learning (Broadbent \& Poon, 2015; Kintu \& Zhu, 2016). With the inevitability of online learning such a conclusion can be exploited in expanding learners' self-regulatory skills to other types of learning. 
The study also proved that students' university level does not affect students' use of self-regulatory strategies. A corresponding conclusion was found by Barnard-Brak et al. (2010) who examined the change of self-regulated learning strategies in a group of first-generation online learners for a semester. Their findings revealed no significant difference in learners' self-regulatory skill over time. Wandler and Imbriale (2017) believed that having mere exposure to online learning is not a relying strategy for enhancing students' self-regulation. Such conclusion sheds light on the indispensable role of the teacher in fostering students' self-regulatory skills. Students may be unable to identify the best self-regulated strategies that fulfill their academic needs; therefore, their achievement is likely to be affected. An aligned view was presented by Sun and Rueda (2012) who asserted the important role of teachers' support in boosting students' emotional engagement in online learning context specially for students who enrolled in online courses for the first time.

Analyzing students' interviews indicated various positive attitudes towards online learning. The students reported their sense of better performance as learners through the online learning experience. A supporting conclusion was drawn by Broadbent and Poon (2015) who investigated the relationship between self-regulatory learning strategies and online academic success. They found that they are positively related. Coincidingly, Puzziferro (2008); Sharma et al. (2007); and Pardo et al. (2016) in their studies revealed that self-regulatory learning strategies highlighted in the management of time and study environment were positively related to enhancing students' performance.

In addition to enhancing performance, students reported improvement in academic achievement. Coinciding results were provided by Sun et al. (2018), and Bradley et al. (2017) who studied the effect of self-regulation and self-efficacy on students' achievement in online learning environment. Findings indicated that students' self-regulatory strategies have a direct impact on their academic outcomes.

Although statistically found to be self-regulated, some students reported a feeling of anxiety and fatigue in their online learning experience. This result contradicts with Naykki et al. (2018) who examined exhaustion and anxiety of 310 students and concluded that self- regulatory strategies represented by high time- and study-environment management strategies had a significant effect in reducing students' feelings of anxiety and exhaustion. This finding also controverts with Lodewyk et al. (2009) who compared low and high academic achievers' performance in two types of tasks; well-structured versus ill-structured and concluded that high achievers scored better than low achievers in both types of tasks and reported higher levels of self-regulation and lower anxiety. However, this result can be justified by external factors such as physical and emotional exhaustion that were stated in students' responses in the interview. Physical exhaustion was reported to be due to excessive screen time which led to eye strain, headache, neck and back pain. Emotional exhaustion resulted from too much student workload or a sudden change in the lesson timing without prior notice.

\section{Conclusion and Recommendations}

Due to the mandatory shift to online learning as a result of the COVID-19 pandemic, it became crucial to investigate how students can cope with such type of learning which is fundamentally learner self-dependent. Successful self-dependent learners are those who demonstrate a high level of self-regulation. Findings of the present study revealed that non-native TEFL university students are high self-regulatory learners in the online learning environment. They show a good command of applying the various types of self-regulatory strategies in online classes. This result uncovers the underlying potentials of the students when taking responsibility of their own learning. Such information could be exploited in other educational settings by giving them more opportunities to take the lead of their learning experience. Therefore, learners could expand the concept of self-regulatory learning to all their learning environments.

The findings of the present study offer pedagogical implications for university teachers. Teachers could play a significant role in raising students' awareness of self-regulatory strategies and getting them more cognitively and emotionally involved in the learning experience. Teachers could also participate in eliminating the psychological pressure that students may be exposed to while trying to self-regulate their learning. This could be attained by providing well-structured lessons, realizing students' needs, avoiding assignments overload and showing understanding of the challenges the students face. Developing such cognizant teachers and conscious learners could lead to high-level self-regulatory learning which in turn has its positive impact on learners' academic performance, achievement and outcomes.

\section{Acknowledgements}

The author would like to thank Deanship of Scientific Research at Majmaah University for supporting this work under Project Number No. R-1441-183. 
I'd like also to thank Dr. Asmaa Almerghani for her useful Youtube Channel from which I consolidated my knowledge and application of statistical analysis. Special appreciation is due to my colleague Dr. Fayza Alhussein for her valuable comments on the study.

\section{References}

Anderson, N. J. (1991). Individual differences in strategy use in second language reading and testing. Modern Language Journal, 75, 460-472. https://doi.org/10.1111/j.1540-4781.1991.tb05384.x

Anderson, N. J. (2002, April). The role of metacognition in second language teaching and learning. ERIC Digest. Washington, DC: Center for Applied Linguistics.

Barnard-Brak, L., Paton, V. O., \& Lan, W. Y. (2010). Profiles in self-regulatory learning in the online learning environment. International Review of Research in Open and Distance Learning, 11(1), 61-80. https://doi.org/10.19173/irrodl.v11i1.769

Bin, X. (2008). Application of learning strategies and college English reading achievements. US-China Foreign Language, 6(5), 39-45.

Bradley, R. L., Browne, B. L., \& Kelley, H. M. (2017). Examining the influence of self-efficacy and self-regulation in online learning. College Student Journal, 51(4), 518-530.

Broadbent, J., \& Poon, W. L. (2015). Self-regulatory learning strategies \& academic achievement in online higher education learning environments: A systematic review. The Internet and Higher Education, 27, 1-13. https://doi.org/10.1016/j.iheduc.2015.04.007

Feryal, C. (2008). How to enhance reading comprehension through metacognitive strategies. The Journal of International Social Research, 1(2), 83-93.

Harris, V. (2003). Adapting classroom-based strategy instruction to a distance learning context. TESL-EJ, 7(2), 1-19. Retrieved May 24, 2020, from http://www.tesl-ej.org/wordpress/issues/volume7/ej26/ej26a1/

Hung, M. L., Chou, C., Chen, C. H., \& Own, Z. Y. (2010). Learner readiness for online learning: Scale development and student perceptions. Computers \& Education, 55(3), 1080-1090. https://doi.org/10.1016/j.compedu.2010.05.004

Khiat, H. (2015). Measuring self-directed learning: A diagnostic tool for adult learners. Journal of University Teaching \& Learning Practice, 12(2), 1-15. Retrieved from http://ro.uow.edu.au/ jutlp/vol12/iss2/2

Kirmizi, O (2015). The influence of learner readiness on student satisfaction and academic achievement in an online program at higher education. The Turkish Online Journal of Educational Technology, 14(1), 133-142. Retrieved from http://www.tojet.net/articles /v14i1/14114.pdf

Kizilcec, R. F., Pérez-Sanagustín, M., \& Maldonado, J. J. (2017). Self-regulatory learning strategies predict learner behavior and goal attainment in Massive Open Online Courses. Computers \& Education, 104, 18-33. https://doi.org/10.1016/j.compedu.2016.10.001

Lodewyk, K. R., Winne, P. H., \& Jamieson - Noel, D. L. (2009) Implications of task structure on self - regulated learning and achievement. Educational Psychology, 29(1), 1-25, https://doi.org/10.1080/01443410802447023

Mason, J. (2002). Qualitative Researching (2nd ed.). London: Sage Publications.

O'Malley, J. M., \& Chamot, A. U. (1990). Learning strategies in second language acquisition. Cambridge, UK: Cambridge University Press. https://doi.org/10.1017/CBO9781139524490

Panadero, E. (2017). A review of self-regulatory learning: Six models and four directions for research. Frontier in Psychology, 8(422). https://doi.org/10.3389/fpsyg.2017.00422

Piia, N., Arto, K. A., Hanna, J., \& Kirsi, P. (2018). Student teachers' feelings of anxiety and exhaustion: can self-regulated learning skills function as an antidote? Educational Research and Evaluation, 24(8), 462-480. https://doi.org/10.1080/13803611.2019.1601571

Pintrich, P. R. (2000). The role of goal orientation in self-regulatory learning. In M. Boekaerts, P. Pintrich \& M. Zeidner (Eds.), Handbook of self-regulation (pp. 451-502). San Diego, CA: Academic. https://doi.org/10.1016/B978-012109890-2/50043-3

Puzziferro, M. (2008). Online Technologies Self-Efficacy and Self-Regulated Learning as Predictors of Final Grade and Satisfaction in College-Level Online Courses. American Journal of Distance Education, 22(2), 72-89. https://doi.org/10.1080/08923640802039024 
Rabiee, F. (2004). Focus-group interview and data analysis. Proceedings of the Nutrition Society, 63, 655-660. https://doi.org/10.1079/PNS2004399

Riazi, A. M., \& Candlin, N. C. (2014). Mixed-methods research in language teaching and learning: Opportunities, issues and challenges. Language Teaching, 47, 135-173. https://doi.org/10.1017/S0261444813000505

Singh, V., \& Thurman, A. (2019). How many ways can we define online learning? A systematic literature review of definitions of online learning (1988-2018). American Journal of Distance Education, 33(4), 289-306. https://doi.org/10.1080/08923647.2019.1663082

Singhal. M. (2001). Reading proficiency, reading strategies, metacognitive awareness and L2 readers. The Reading Matrix, 1(1), 1-13.

Sun, Z., Xie, K., \& Anderman, L. H. (2018). The role of self-regulatory learning in students' success in flipped undergraduate math course. The Internet and Higher Education, 36, 41-53. https://doi.org/10.1016/j.iheduc.2017.09.003

Tzohar-Rozen, M., \& Kramarski, B. (2014). Metacognition, Motivation, and Emotions: Contribution of Self-Regulated Learning to Solving Mathematical Problems. Global Education Review, 1(4), 76-95.

Williamson, G. (2015). Self-regulated learning: an overview of metacognition. Journal of Initial Teacher Inquiry, 1, 25-27. Retrieved from http://hdl.handle.net/10092/11442

Winne, P. H., \& Perry, N. E. (2000). Measuring self-regulated learning. In M. Boekaerts, P. R. Pintrich \& M. Zeidner (Eds.), Handbook of self-regulation (pp. 531-566). San Diego, CA: Academic Press. https://doi.org/10.1016/B978-012109890-2/50045-7

Zhu, Y., Au, W., \& Yates, G. (2016). University students' self-control and self-regulatory learning in a blended course. The Internet and Higher Education, 30, 54-62. https://doi.org/10.1016/j.iheduc.2016.04.001

Zimmerman, B. (2000). Attaining self-regulation: A social cognitive perspective. In M. Boekaerts, P. Pintrich \& M. Zeidner (Eds.), Handbook of self-regulation (pp. 13-39). San Diego, CA: Academic. https://doi.org/10.1016/B978-012109890-2/50031-7

Zimmerman, B. (2013). From Cognitive Modeling to Self-Regulation: A Social Cognitive Career Path. Educational Psychologist, 48(3), 135-147. https://doi.org/10.1080/00461520.2013.794676

Zimmerman, B., \& Pons, M. (1986). Development of a Structured Interview for Assessing Student Use of Self-Regulated Learning Strategies. American Educational Research Journal, 23(4), 614-628. https://doi.org/10.3102/00028312023004614

Zimmerman, B. J., \& Schunk, D. H. (2011). Handbook of Self-Regulation of Learning and Performance. New York, NY: Routledge.

\section{Copyrights}

Copyright for this article is retained by the author, with first publication rights granted to the journal.

This is an open-access article distributed under the terms and conditions of the Creative Commons Attribution license (http://creativecommons.org/licenses/by/4.0/). 